\title{
A COMPARISON OF INTRACAESARIAN VERSUS INTERVAL PLACEMENT OF INTRAUTERINE CONTRACEPTIVE DEVICE
}

\author{
Uzma Gul, Sunarays Akhtar \\ PAF Hospital, Shahbaz, Jacobabad/National University of Medical Sciences (NUMS) Pakistan
}

\begin{abstract}
Objective: To compare intra caesarian placement of intrauterine contraceptive device with interval placement at 6 weeks in terms of device expulsion and continued use at 6 months postpartum.

Study Design: Quasi experimental study.

Place and Duration of Study: Obstetrics and Gynecology department, Combined Military Hospital Jhelum, from Oct 2017 to Oct 2018.

Methodology: One hundred and four pregnant women aged 20 to 40 years old, planned for an elective caesarian delivery and who opted for an intrauterine contraceptive device were included. They were randomly divided into two equal groups using lottery method. Women were told about their assigned timing of device placement well before their surgery. Group A had device placed during caesarian section while group B (serving as controls) had insertion after 6 weeks. Copper T 380 A was provided free of charge to all participants. Women were seen after 6 weeks, 3 months and 6 months. Both groups were analyzed and compared in terms of device expulsion and continued use at 6 months postpartum.

Results: The device was placed successfully in 48 women in group A and 35 women in group B $(p$ 0.001). There was no statistically significant difference in device expulsion rates between the two groups ( $p$ 0.37). After 6 months significantly higher proportion of women in the intracaesarian group were continuing to use the intrauterine contraceptive device as compared to the interval group $(p<0.05)$.

Conclusion: Intracaesarian placement of intrauterine contraceptive device leads to statistically significant higher continuation rates as compared to conventional interval placement with no statistically significant difference in expulsion rates.
\end{abstract}

Keywords: Contraception, Intrauterine devices, Postpartum period.

This is an Open Access article distributed under the terms of the Creative Commons Attribution License (http://creativecommons.org/licenses/by/4.0), which permits unrestricted use, distribution, and reproduction in any medium, provided the original work is properly cited.

\section{INTRODUCTION}

The time period immediately after child birth is ideal to discuss and start contraception. The intrauterine contraceptive device (IUCD) can be conveniently placed in the post-partum period and have minimal negative effects on lactation. Immediate post placental insertion of IUCD, that is, insertion performed within 10 minutes after placental delivery, has been in practice for more than 40 years and quite good results have been reported including low rates of expulsion ${ }^{1}$.

Effective contraception should ideally be started immediately after delivery as fertility can resume soon after delivery and also women may find it difficult to return for a separate visit for

Correspondence: Dr Uzma Gul, Classified Gynaecologist, PAF Hospital, Shahbaz, Jacobabad Pakistan

Received: 31 Dec 2019; revised received: 13 Feb 2020; accepted: 19 Feb 2020 contraceptive advice while recovering from delivery and caring for the newborn ${ }^{2}$. The traditional practice of delaying the initiation of contraception till 6 weeks not only causes an excellent opportunity to be missed but also leads to waning motivation on part of the women ${ }^{3}$. In those women who are not breast feeding, almost half start to ovulate by about 6 weeks after delivery 4 , thus timely use of an effective form of contraception is of utmost importance to prevent unplanned pregnancies 5 .

Recently there has been rising advocacy for the use of long-acting reversible contraception (LARC) which includes the long lasting and reversible methods like IUCDs and implants. The LARC methods nearly eliminate the risk of failure due to noncompliance ${ }^{6}$. LARCs are the firstline contraception for young women as they are 
safe, easily reversible and associated with a very low failure rate ${ }^{7}$. When a pregnant woman opts for a LARC method after delivery, initiation immediate post-partum should be discussed as they are a secure and efficacious option for these women associated with very low failure rates ${ }^{8,9}$.

The purpose of this study was to compare intra-caesarian IUCD placement with conventional interval placement at 6 weeks in terms of expulsion and continued use of the IUCD at 6 months postpartum.

\section{METHODOLOGY}

This quasi experimental study was carried out at the Gynae/Obs department of Combined Military Hospital Jhelum, from Jun 2017 to Oct 2018. Approval was taken from the hospital's ethics review committee. Pregnant women 20 to 40 years of age who were planned for an elective caesarian section at term and wanted to have an IUCD placed were enrolled. Women with history of pelvic inflammatory disease, known uterine anomaly distorting the uterine cavity e.g fibroid were excluded.

Sample size was calculated using WHO sample size calculator. We expected that $65 \%$ women in the interval group and $85 \%$ in the intra-caesarian group would be using the IUCD at the final 6 months follow up visit ${ }^{16}$. Hypothesis test for two population proportions (2 sided test) was used with level of significance (a) of $5 \%$ and power of $90 \%$. Non probability consecutive sampling technique was used. Written and informed consent was taken from all women. After enrollment women were randomized to intra-caesarian placement of IUCD (group A) or interval placement after 6 weeks (group B), using lottery method. Women were told about their assigned allocation of the timing of IUCD placement well before their caesarian section. Women in both groups were placed a $\mathrm{Cu}-\mathrm{T} 380 \mathrm{~A}$ which was provided free of charge. All women received routine antenatal care. Additional exclusion criteria that were assessed at the time of delivery for post enrollment ineligibility were chorioamnionitis or ruptured membranes for more than 24 hours before delivery, preterm delivery <37 weeks, post-partum hemorrhage (as defined by the need for transfusion, estimated blood loss of more than $1000 \mathrm{ml}$, requirement for uterotonic medications in addition to the routine prophylactic use of Oxytocin during third stage) or participants declining an IUD placement.

All women had caesarian section at term (after completion of 37 weeks). In group A, women had the IUCD placed during the caesarian section after the baby and placenta were delivered. The IUCD was inserted through the caesarian incision, placed into the uterine fundus and strings were directed into the cervix using a forceps. All women received broad spectrum antibiotic cover and adequate analgesia. The women were discharged from the hospital on the second post-operative day.

All the women were called for follow up after 6 weeks. Women in group B had the IUCD placed at this time under aseptic conditions. A bimanual examination was performed, size of the uterine cavity was assessed and then the device was carefully placed. Women in group A who had their IUCD already in place were asked about history of expulsion. A speculum examination was done to visualize the threads of IUCD and if they could not be seen then an ultrasound was done to localize the IUCD.

The next follow-up visit of all the women was at 3 months and then at 6 months. Women were inquired about the primary method of contraception being used, history of expulsion and whether any of the participants had their device removed electively. A pelvic examination was carried out, followed by an ultrasound if threads could not be seen.

Primary outcomes were device expulsion and continued use of the device at 6 months in both groups. Expulsion was defined as IUCD not in the uterine cavity, when either the patient gave a clear history of expulsion or failure to visualize the IUCD on speculum examination and ultrasound. Continued use was defined as the number of study participants still using the IUCD as a 
method of contraception on the 6 months followup visit. Secondary outcome included successful device placement in both groups.

The data was analyzed using SPSS 21. Mean \pm SD were calculated for quantitative variables. Ratios and percentages were calculated for qualitative variables. Proportions were compared using chi square test $(p \leq 0.05$ was considered significant).

\section{RESULTS}

One hundred and fifteen women were enrolled, out of whom 104 were found to be eligible and were randomized into two equal groups ficant ( $p$ 0.001) which proves that in our setting many women fail to start effective contraception if this is delayed till their postpartum visit.

The device was found to be expelled in 5 out of the 48 women of group A and in 6 out of 35 women of group B. The difference was not statistically significant ( $p 0.37)$.

The continued use of the IUCD at 6 months postpartum was shown in table-II. Five women in group A and 9 women in group B were lost to follow up by the end of the follow up period ( $p$ $0.25)$. If lost to follow up were excluded from the analysis, the continued use in group A was 38

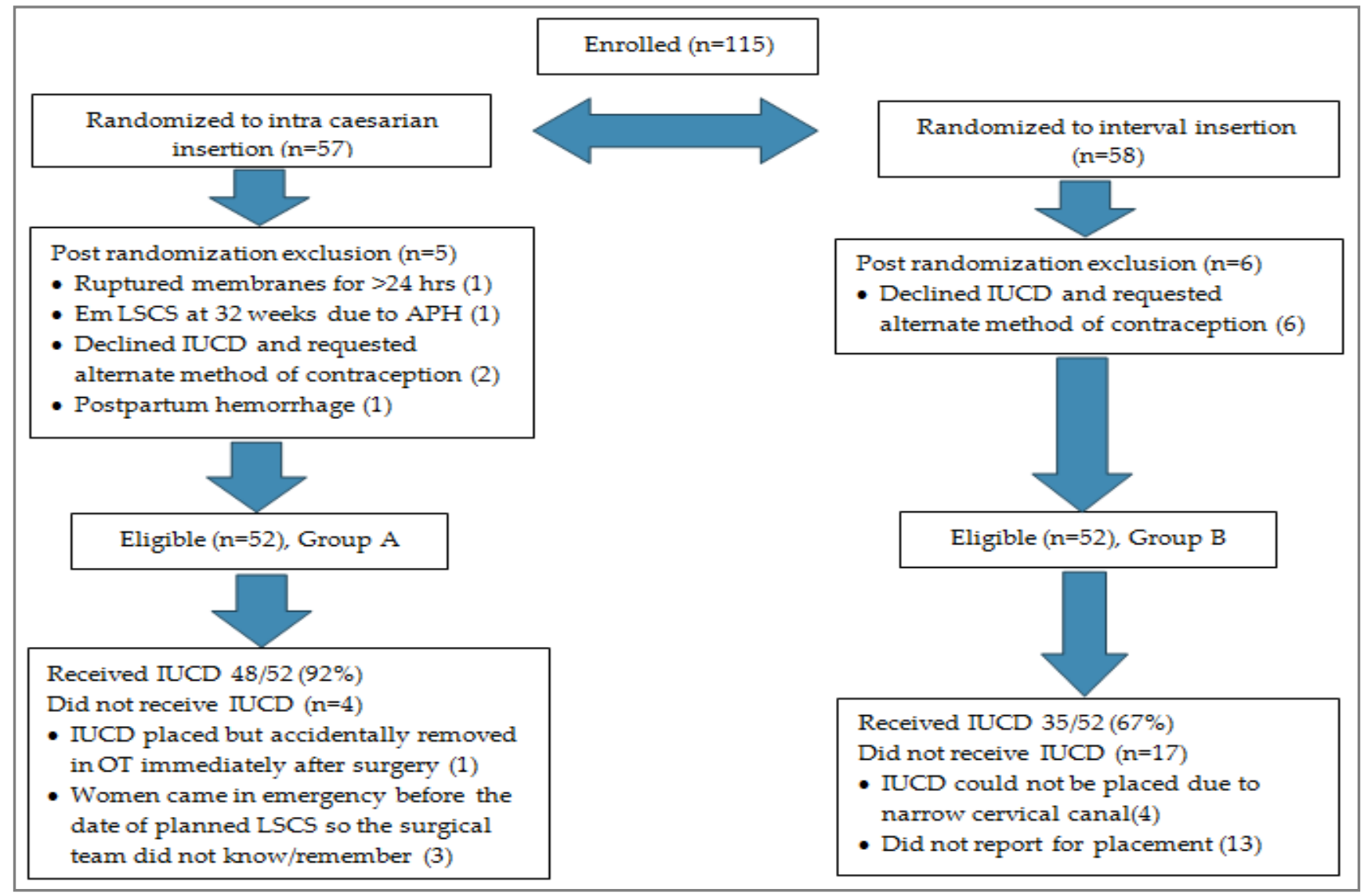

Figure-1: Study flow diagram.

as shown in fig-1. Baseline characteristics of both groups were shown in table-I.

As shown in fig- 1 the device was placed successfully in 48 out of 52 women in group A. In group B 35 out of 52 women had a successful interval insertion of the IUCD. The difference between the two groups was statistically signi- out of $47(81 \%)$ compared with 20 out of $43(47 \%)$ in group B ( $p$ 0.0002). If lost to follow up were counted as failures, then the continued use was 38 out of $52(73 \%)$ in group A and 20 out of 52 $(38 \%)$ in group B ( $p$ 0.0003). If we presume that those lost to follow up were continuing to use the IUCD, then the continuation in group A was 
$43 / 52(83 \%)$ and in group B it was 29/52 (56\%) ( $p$ $0.0029)$. Thus in all the scenarios (i.e whether lost to follow up were excluded from analysis, counted as failures or counted as continued use) the continuation of IUCD in the intracaesarian group

Table-I: Baseline characteristics of study participants.

\begin{tabular}{|c|c|c|}
\hline Baseline Characteristics & $\begin{array}{c}\text { Group A } \\
(n=52)\end{array}$ & $\begin{array}{c}\text { Group B } \\
(n=52)\end{array}$ \\
\hline Age (Mean \pm SD) (year) & $32.5 \pm 4.3$ & $32.4 \pm 4.1$ \\
\hline \multicolumn{3}{|l|}{ Parity } \\
\hline 1 & $2(3.8 \%)$ & $3(5.7 \%)$ \\
\hline 2 & $11(21.1 \%)$ & $6(11.5 \%)$ \\
\hline$>2$ & $39(75 \%)$ & $43(82.6 \%)$ \\
\hline $\begin{array}{l}\text { Previous use of } \\
\text { intrauterine } \\
\text { contraceptive device }\end{array}$ & $18(34.6 \%)$ & $15(28.8 \%)$ \\
\hline
\end{tabular}

was significantly higher as compared to the interval group ( $p$-value 0.0002, 0.0003 and 0.0029 respectively) as shown in table-II.
Several studies have been done to compare immediate post placental and interval insertion of IUCD but our study was specifically aimed to see whether placement of an IUCD during the caesarian section was associated with higher continuation rates as compared to interval placement at 6 weeks and also to compare intra-caesarian and interval placement in terms of device expulsion.

We found that in women who were scheduled to undergo a caesarian delivery and wanted a long term contraception, the time of caesarian section was a golden opportunity to place an IUCD because at this time these women were under the direct care of a health care team. Due to several domestic and local barriers many of these women never get an opportunity to return for a postpartum visit. In a study by Zerden et al the authors concluded that $65 \%$ of women interested in a post-partum LARC did not receive it, the most common reason being the need for a sepa-

Table-II: Comparison of intra-caesarian and interval placement of intrauterine contraceptive device.

\begin{tabular}{l|c|c|c}
\hline & $\begin{array}{c}\text { Group A (Intracaesarian } \\
\text { placement) (n=52) }\end{array}$ & $\begin{array}{c}\text { Group B (Interval } \\
\text { placement) (n=52) }\end{array}$ & $\boldsymbol{p}$-value \\
\hline Intrauterine contraceptive device placement & $48 / 52(92.3 \%)$ & $35 / 52(67.3 \%)$ & 0.001 \\
\hline Intrauterine contraceptive device expulsion & $5 / 48(10.4 \%)$ & $6 / 35(17.1 \%)$ & 0.37 \\
\hline Lost to follow up at 6 months & $5 / 52(9.6 \%)$ & $9 / 52(17.3 \%)$ & 0.25 \\
\hline Continued Use at 6 months & \multicolumn{3}{|c}{} \\
\hline If lost to follow up excluded from data & $38 / 47(80.8 \%)$ & $20 / 43(46.5 \%)$ & 0.0002 \\
If lost to follow up counted as failures & $38 / 52(73 \%)$ & $20 / 52(38.4 \%)$ & 0.0003 \\
If lost to follow up counted as continued use & $43 / 52(82.6 \%)$ & $29 / 52(55.7 \%)$ & 0.0029 \\
\hline
\end{tabular}

\section{DISCUSSION}

IUCDs are a secure and efficacious form of long term reversible contraception and thereby help to reduce the rate of unplanned pregnancies. Immediate post placental insertion of IUCD is defined as device insertion within 10 minutes of the delivery of placenta 10 in contrast to interval insertion which has been traditionally done 6 weeks postpartum ${ }^{11}$. When performed by a trained practitioner, immediate post-placental insertion is associated with fairly low expulsion rates ${ }^{12}$. IUCDs can be safely placed in women who undergo a caesarian delivery as there is no evidence that they are affected by caesarian section nor do they have any negative impact on lactation ${ }^{13}$. rate post-partum visit. They proposed to eliminate the two visit protocol for post-partum LARC insertion in order to increase their use ${ }^{14}$. In our study the IUCD was placed in 92\% women during the caesarian section in contrast to $67 \%$ women who were scheduled for interval placement $(p 0.001)$. This highlighted the fact that if the initiation of contraception is delayed till 6 weeks than a large proportion of women fail to come back. Paul et al also concluded that IUCD placement during caesarian section is an important intervention that can reduce the rate of unplanned pregnancies by avoiding the need for a separate postpartum visit ${ }^{15}$.

The IUCD continuation rates in our study were significantly higher for intra-caesarian 
placement versus interval placement $(p<0.05)$. Similar results have been reported by Levi et al who found that when IUCD was placed during a caesarian section, it led to a higher proportion of women $(83 \%)$ using the IUCD at 6 months postpartum as compared to women who planned for an interval placement of IUCD (64\%). Thus they concluded that this strategy of placing the IUD during the caesarian section provides the women with an excellent option without the need for a separate visit in the postpartum period ${ }^{16}$. In another study conducted by Chhari et al the authors found that immediate post placental insertion of IUCD was not associated with increased rates of pelvic pain, infection or bleeding. They also reported nil device expulsion rate in the women in whom the device was placed during the caesarian section $(p 0.037)^{11}$. High fundal placement of the IUCD is recommended to reduce the device expulsion rates ${ }^{12}$ which is particularly easy to ensure when the device is being placed during a caesarian section as the obstetrician has clear access to the uterine cavity at this time. Celen et al reported $81.6 \%$ continuation rate at 6 months when IUCD was placed during caesarian section and at the same time reported no serious complications ${ }^{17}$.

Kapp et al conducted a systematic review of IUCD insertions in the postpartum period and concluded that lower expulsion rates are observed with intra-caesarian placement of IUCD as compared to immediate insertion following vaginal delivery without any rise in the postoperative complication rate ${ }^{18}$. In our study we observed no significant difference in the expulsion rates between the two groups ( $p$ 0.37). Intra-caesarian placement of IUCD was previously discouraged due to fear of expulsion and high rate of complications but these fears have proved unfounded. In a study by Khokar et al the authors concluded that intra-caesarian insertion of IUCD was a very safe method with low rates of expulsion $(2.1 \%)$, high satisfaction $(70 \%)$ and high continuation rates at 6 months follow up ${ }^{19}$. Similar results have been observed in our study.
Contraceptive counselling which is routinely done postpartum should ideally be done during the antenatal visits so that women who are interested in getting postpartum LARCs can be provided in the immediate postpartum period both after vaginal delivery and caesarian section. In our study a large number of women in the interval insertion did not get the device placed, which is a limitation of this study. We feel that one contributory factor could be poor attendance of our patients at the antenatal clinics due to which adequate contraceptive counselling fails to be done. Future research can be aimed at effect of antenatal counselling on the rate of uptake of immediate post-partum LARCs, satisfaction, complications and discontinuation rates of IUCDs placed during caesarian section.

\section{CONCLUSION}

It is therefore concluded that the insertion of an IUCD during a caesarian section leads to statistically significant higher continuation rates at 6 months postpartum as compared to interval placement. Women who are planned to undergo a caesarian section and want a long term contraception the IUCD can be safely placed at the time of caesarian surgery without any significant increase in the device expulsion rates.

\section{CONFLICT OF INTEREST}

This study has no conflict of interest to be declared by any author.

\section{REFERENCES}

1. Xu JX, Reusche C, Burdan A. Immediate postplacental insertion of the intrauterine device: A review of Chinese and the world's experiences. Adv Contracept 1994; 10(1): 71-82.

2. Millar SL, Cameron ST. Contraception in women with medical conditions. Obstet Gynaecol Reprod Med 2019; 29(4): 111-17.

3. Tocce KM, Sheeder JL, Teal SB. Rapid repeat pregnancy in adolescents: do immediate postpartum contraceptive implants make a difference? Am J Obstet Gynecol 2012; 206(6): 481-e1-7.

4. Speroff L, Mishell DR. The postpartum visit: it's time for a change in order to optimally initiate contraception. Contraception 2008; 78(2): 90-98.

5. Moniz M, Chang T, Heisler M, Dalton VK. Immediate postpartum long-acting reversible contraception: the time is now. Contraception 2017; 95(4): 335-38.

6. Stoddard A, McNicholas C, Peipert JF. Efficacy and safety of long-acting reversible contraception. Drugs 2011; 71(8): 969-80.

7. Temple-Smith M, Sanci L. LARCs as first-line contraception What can general practitioners advise young women? Aust Fam Physician 2017; 46(10): 710-15 
8. Taub RL, Jensen JT. Advances in contraception: new options for postpartum women. Expert Opin Pharmacother 2017; 18(7): 677-88.

9. Goldthwaite LM, Shaw KA. Immediate postpartum provision of long-acting reversible contraception. Curr Opin Obstet Gynecol 2015; 27(6): 460-64.

10. Chen BA, Reeves MF, Hayes JL, Hohmann HL, Perriera LK, Creinin MD. Post placental or delayed insertion of the levonorgestrel intrauterine device after vaginal delivery: a randomized controlled trial. Obstet Gynecol 2010; 116(5): 1079-87.

11. Chhari A, Zutshi V, Sharma R, Batra S. Comparison of postplacental IUD with interval IUD. Int J Reprod Contracept Obstet Gynecol 2015; 4(4): 1090-93.

12. O'Hanley K, Huber DH. Postpartum IUDs: keys for success. Contraception 1992; 45(4): 351-61.

13. Goldstruck ND, Steyn PS. Intrauterine contraception after caesarian section and during lactation: a systematic review. Int J Womens Health 2013: 5(1); 811-18.
14. Zerden ML, Tang JH, Stuart GS, Norton DR, Verbiest SB. Barriers to receiving long-acting reversible contraception in the postpartum period. Womens Health Issues 2015; 25(6): 616-21.

15. Paul B, Lisa G. Intrauterine device insertion during caesarian delivery: The rising tide of the postdelivery intrauterine device. Obstet Gynecol 2015; 126(1): 1-2.

16. Levi EE, Stuart GS, Zerden ML, Garrett JM, Bryant AG. Intrauterine device placement during cesarean delivery and continued use 6 months postpartum: A randomized controlled trial. Obstet Gynecol 2015; 126(1): 5-11.

17. Celen S, Sucak A, Yildiz Y, Danisman N. Immediate post placental insertion of an intrauterine contraceptive device during caesarian section. Contraception 2011; 84(3): 240-43.

18. Kapp N, Curtis KM. Intrauterine device insertion during the postpartum period: a systematic review. Contraception 2009; 80(4):327-36.

19. Khokar S, Rizwan W. Complications and safety of intracaesarian insertion of IUCD. Pak J Med Health Sci 2018; 12(1): 595-97. 